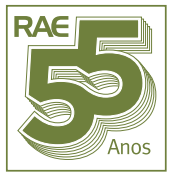

ESPECIAL RAE

Artigo convidado

DOI: http://dx.doi.org/10.1590/So034-759020170406

\title{
PERIÓDICOS BRASILEIROS DA ÁREA DE ADMINISTRAÇÃO NO CONTEXTO DE INTERNACIONALIZAÇÃO DA PRODUÇÃO CIENTÍFICA
}

\section{INTRODUÇÃO}

Este ensaio é fruto da experiência do autor como editor-chefe da RAE-Revista de Administração de Empresas entre 2009 e 2015 , e reflete a sua visão sobre a gestão do processo editorial científico, sobre mecanismos de disseminação da produção científica, sobre estratégias de internacionalização dos periódicos brasileiros e sobre a necessidade de uma política de internacionalização para os periódicos brasileiros da área de administração.

Alguns dos temas expostos neste ensaio já foram apresentados, de uma forma ou de outra, em editoriais produzidos ao longo dos anos como editor-chefe e contam também com elementos coletados de alguns estudos existentes sobre gestão de periódicos e modelos de negócio relacionados a disseminação do conhecimento científico. Sem a pretensão de esgotar o tema, este ensaio quer apenas contribuir para o debate sobre a inevitável internacionalização da produção científica brasileira.

Para entender a internacionalização dos periódicos brasileiros, é preciso aceitar que ela já está aí diante de nós, quer queiramos, gostemos ou não. Isso porque a internacionalização não é um projeto ou ação isolada de um periódico, e sim um contexto de produção acadêmica, da qual a disseminação do trabalho de pesquisa que compete aos periódicos é apenas um aspecto. Na prática, a partir do momento em que os pesquisadores brasileiros submetem seus artigos a periódicos estrangeiros, os periódicos brasileiros já estão em contexto de internacionalização.

Para que não sejam preteridos diante de seus equivalentes internacionais, os periódicos nacionais têm que sair da condição de expectadores e desenvolver estratégias próprias de internacionalização. Isso significa criar ações que indiquem claramente como se posicionar para disseminar pesquisa científica de qualidade, seja ela produzida originalmente no Brasil ou em outros países.

A despeito do modelo de incentivo para internacionalização dominante no Brasil, que prestigia, em geral, de maneira pouco criteriosa os periódicos internacionais em detrimento dos nacionais, existe a oportunidade para os gestores de nossos periódicos criarem estratégias compatíveis com os interesses de nossa comunidade acadêmica. Afinal, para que uma comunidade científica se desenvolva, é necessário que haja um número significativo de periódicos no seu entorno. Para além das estratégias individuais dos periódicos, nossa comunidade precisa de políticas institucionais que considerem o papel dos periódicos nacionais na internacionalização da produção científica brasileira.
EDUARDO H. DINIZ

eduardo.diniz@fgv.br

Professor da Fundação Getulio

Vargas, Escola de Administração

de Empresas de São Paulo - São

Paulo-SP, Brasil 


\section{AS ETAPAS DO PROCESSO EDITORIAL CIENTÍFICO}

Antes de nos aprofundarmos nas questões específicas da internacionalização, precisamos, em primeiro lugar, entender três dinâmicas muito específicas existentes no processo editorial de periódicos acadêmicos: a certificação, a gestão editorial e o pós-publicação (Dubini, Trani, \& Micheli, 2011) Apesar de estarem enredadas no processo de gestão do periódico, entender essas três dinâmicas de maneira separada permite analisar com mais precisão os limites e possibilidades de internacionalização dos periódicos brasileiros.

A certificação é a parte mais eminentemente científica do processo e é voltada para garantir a qualidade dos artigos, com foco na sua contribuição a um campo acadêmico. A certificação é capitaneada por um comitê científico comprometido e de reconhecida liderança em uma determinada comunidade acadêmica, normalmente composto pelo editor-chefe, editores associados e um corpo de revisores ad hoc. As atividades de certificação de um artigo são fundamentalmente apoiadas em trabalho voluntário de editores associados e revisores, de acordo com a tradição científica. Em alguns casos, devido ao tempo de dedicação e esforço exigido na coordenação de atividades que vão além da certificação, é aceitável e, às vezes, até desejável que $o$ editor-chefe receba alguma remuneração, diferentemente do que acontece com os outros membros do comitê científico.

Indicadores de quantidades e origem das submissões e taxa de aprovação, por exemplo, são importantes para o monitoramento dessa etapa. Entretanto, o que faz a diferença para a gestão da certificação é o controle dos prazos envolvidos nesse processo. Ainda que se reconheça que um tempo, medido em meses, seja necessário entre a submissão de um artigo científico até a sua efetiva publicação, há que se controlar os tempos envolvidos nesse processo para que ele não se arraste demasiadamente e produza efetiva contribuição para os autores e suas pesquisas, inclusive nos casos de rejeição de artigos. 0 comprometimento com prazos e a alta qualidade da contribuição oferecida pelos revisores para a melhoria do artigo demonstram respeito ao trabalho dos autores e aos objetivos daquele periódico específico, e são fundamentais para a valorização do periódico, particularmente na comparação com os seus correlatos internacionais.

Algumas normas de conduta ajudam a orientar o trabalho da certificação. 0 manual de Boas Práticas da Publicação Científica produzido pela Associação Nacional de Pós-Graduação e Pesquisa em Administração (ANPAD, 2017), embora seja um bom exemplo de normas de conduta para a certificação, não trata de todo o processo de publicação, como sugere o seu título.
Nesse caso, o mais correto seria nomear esse manual como Boas Práticas da Certificação Científica, pois consideramos que todo o processo de publicação deve incluir também a gestão editorial e a pós-publicação.

Confundir o processo de certificação com todo o processo editorial induz a equívocos ao se pensar em políticas para os periódicos. Existe, de fato, um processo de gestão de documentos na fase de certificação, associada ao controle do envio de artigos aos editores associados, revisores e autores, incluindo os devidos pareceres. Entretanto, essa gestão de documentos é tarefa que deve ser considerada atividade de gestão editorial. Documentos utilizados como critérios de avaliação de periódicos produzidos pela Scientific Electronic Library Online (SciELO, 2014) e Coordenação de Aperfeiçoamento de Pessoal de Nível Superior (Capes, 2007) colocam como condição que esse processo de gestão de documentos seja controlado por sistemas automatizados.

0 que não está nesses critérios de avaliação, entretanto, é a discussão sobre potencial ganho de escala e consequente redução de custos na gestão dos periódicos, se a equipe de gestão editorial puder gerenciar o processo de gestão de documentos da fase de certificação para um grupo de periódicos, e não para cada periódico individualmente (Dubini et al., 2011).

De qualquer forma, uma vez certificado, ou seja, "aprovado para publicação", um artigo necessita de revisão do texto, formatação e ajustes diversos necessários para melhorar a apresentação do conteúdo do artigo já aprovado antes que ele seja efetivamente publicado. Essas atividades de editoração, juntamente com as de gestão de manuscritos, são atividades no âmbito da gestão editorial.

Diferentemente da certificação, na gestão editorial, o trabalho profissionalizado tende a gerar maior eficiência, pois é um esforço que gera custos relacionados a trabalho de profissionais do mercado editorial, como acontece com qualquer outro tipo de publicação não científica. Como a qualidade da apresentação dos artigos valoriza um periódico e consequentemente contribui para o seu processo de internacionalização, essas atividades não deveriam ser realizadas de maneira amadora ou voluntária.

Boa parte das atividades da gestão editorial é geralmente terceirizada, cabendo à equipe do periódico a interação com provedores de serviços especializados necessários para produzir uma publicação. Por não estar diretamente relacionada com a identidade do periódico, também na gestão dessas atividades há sensivel ganho de escala caso a equipe editorial responsável cuide de vários periódicos ao mesmo tempo (Dubini et al., 2011).

Enquanto a certificação foca o conteúdo, garantindo a qualidade científica, as atividades de gestão da publicação tratam da forma, garantindo a qualidade gráfica (impressa ou digital) do 
processo editorial científico. Como em qualquer outro processo editorial, publicar um periódico científico demanda cuidado com muitos detalhes, desde padronização de referências, tratamento da linguagem e das imagens, e outros tantos detalhes de formato que contribuem não só para melhorar a legibilidade de um artigo acadêmico, como também para facilitar o processo de indexação, necessária na fase de pós-publicação.

A pós-publicação está relacionada com o esforço de divulgação e aumento da visibilidade dos artigos publicados pelo periódico, e demanda o monitoramento quantitativo e qualitativo de vários indicadores (acesso, citação, espaços de divulgação etc.). Alguns consideram, nessa etapa, também o “marketing científico", por estar associada com as atividades que procuram dar visibilidade ao trabalho feito nas etapas anteriores de certificação e publicação.

De fato, se não houver um trabalho sistemático de póspublicação, pouco adianta ter um artigo de qualidade aprovado e formatado competentemente, pois poucos ficarão sabendo da sua existência. Quanto mais um periódico consegue promover seu produto, os artigos, mais valorizado ele passa a ser. Outro aspecto relevante da pós-publicação é a preservação da memória científica, o que transforma o acervo de um periódico no seu principal ativo.

Com o crescimento do uso de mídias eletrônicas em processos editoriais, produção de vídeos e divulgação para redes sociais se tornam cada vez mais importantes para a disseminação do conhecimento científico. Nos critérios de avaliação do SciELO (2014), há um item específico denominado "Marketing e Divulgação", demandando que os periódicos desenvolvam um plano de disseminação "utilizando o Twitter, o Facebook e/ou outros sistemas". Apesar da sua inegável importância, a produção de peças de divulgação nessas novas mídias encarece o processo editorial e demanda serviços de terceiros ainda mais especializados.

Ao descrevermos as três dinâmicas do processo editorial científico para estabelecer as dimensões de atuação de um periódico acadêmico, pretendemos identificar o papel de cada uma na construção de um periódico com visibilidade internacional. Se a certificação é aquela que dá identidade ao periódico, a gestão editorial contribui para a melhoria da qualidade da publicação, e a pós-publicação objetiva aumentar a visibilidade dos artigos e cuida também do acervo do periódico.

Como efeito prático do entendimento das diferentes dinâmicas do processo editorial científico, é particularmente importante entender como a gestão editorial possui papel central na coordenação do conjunto de atividades inter-relacionadas que vão da certificação até a pós-publicação. Como foi dito anteriormente, a gestão editorial profissionalizada é essencial para garantir a qualidade de todo o processo editorial científico.

\section{DISSEMINAÇÃO DO CONHECIMENTO CIENTÍFICO VIA REPOSITÓRIOS}

Entendidas as dinâmicas da produção editorial científica, vamos aprofundar a discussão sobre um dos mecanismos essenciais na disseminação do conhecimento científico, os repositórios (ou bases) de periódicos. Esses repositórios podem ser compreendidos como elementos de conexão com o ecossistema de disseminação do conhecimento científico e devem ser considerados parte essencial da fase de pós-publicação de qualquer periódico científico.

Não está no escopo deste ensaio apresentar uma tipologia completa dos repositórios, mas é útil entender algumas das características e influências de alguns deles na vida dos periódicos. Alguns repositórios são institucionais, e muitos periódicos participam deles de maneira compulsória. Além de orientar para um certo padrão dentro de determinada instituição, esses repositórios são particularmente importantes para periódicos com poucos recursos para investir numa plataforma de divulgação própria. Um exemplo é aquele organizado pela Biblioteca Digital da FGV (http://bibliotecadigital.fgv.br), que agrega todos os periódicos patrocinados por aquela instituição.

Um segundo tipo de repositório tem a sua importância relacionada diretamente à produção de índices de pós-publicação. Pelo seu foco nos índices, esses repositórios são também são conhecidos como “indexadores”. Muitas vezes organizados para ajudar no compartilhamento de custos na produção de índices ou na tentativa de ajudar a promover periódicos que têm poucos recursos de divulgação, esses repositórios têm o papel muito importante de avaliar a produção científica de uma comunidade considerando todos os periódicos existentes, e não apenas os considerados mais relevantes, fator importante na era das caudas longas (Anderson, 2006). Um exemplo desse tipo de repositório é o SPELL (http://www.spell.org.br).

Há também os repositórios mais seletivos no qual os periódicos têm que se esmerar para comprovar a sua qualidade e, assim, conquistar a oportunidade de compartilhar espaço privilegiado entre os melhores de uma área de conhecimento. Nesses repositórios, a questão vai além do compartilhamento de custos ou de mais um espaço de divulgação. Estar indexado num desses repositórios objetiva obter um selo de qualidade para o periódico, o que garante reconhecimento por toda a comunidade científica. Um exemplo desse tipo de repositório é o SciELO (http://www.scielo.br).

Um quarto tipo de repositório importante de ser entendido, particularmente no contexto de internacionalização, é uma combinação dos dois últimos. Como o segundo tipo descrito 
acima, esses repositórios têm foco na produção de índices, e não na divulgação dos artigos, e também são restritos a um seleto grupo de periódicos que preenchem uma série de requisitos de qualidade, como o terceiro tipo descrito. Entre esses, os mais importantes são os que publicam os índices Journal Citation Reports (JCR) e SCImago Journal Rank (SJR).

Os critérios de qualidade considerados por esses repositórios mais seletivos estão diretamente relacionados às dinâmicas do processo editorial científico mencionadas anteriormente. De uma forma geral, embora haja alguma controvérsia sobre a avaliação dos critérios de qualidade exigidos em cada repositório, aqueles periódicos que mantêm um bom padrão em seu processo editorial completo têm maior possibilidade de ser aceitos (ou indexados) nesses repositórios mais seletivos.

De modo geral, um periódico deve participar do maior número de repositórios que puder, pois cada repositório representa um ecossistema diferente e permite conexão com comunidades científicas em uma diversificada gama de redes acadêmicas. Ao participar desses repositórios, o periódico garante um nível de padronização e monitoramento externo sobre o seu desempenho, e aumenta sua visibilidade ao ampliar a participação nos espaços de disseminação científica. A participação nos repositórios mais seletivos, considerados por universidades e instituições de fomento em todo o mundo no estabelecimento de políticas de incentivo ou de acesso a recursos de pesquisa, representam um caminho necessário para a internacionalização de um periódico.

\section{MODELOS DE ASSINATURA VERSUS ACESSO ABERTO}

O modelo de periódicos que conhecemos atualmente teve origem no século XVII, como um sistema intermediário entre os livros e a troca de cartas, usado pelos acadêmicos da época na disseminação do conhecimento científico (Solomon, 2013). Mais de um século depois, o sistema de avaliação por pares passou a ser integrado ao modelo nascente de periódicos, principalmente com o objetivo de preservar o bom nome das associações científicas que os publicavam.

Editoras comerciais passaram a dominar esse mercado de maneira mais sistemática apenas na segunda metade do século $X X$, explorando o crescente e rentável negócio de assinaturas, enquanto associações científicas se multiplicavam e ampliavam exponencialmente o número de periódicos disponíveis. A partir de meados nos anos 1990, com a internet, começou também a ficar mais comum o uso do meio digital para a disseminação do conhecimento científico. Não demorou para que editoras comerciais passassem, então, a investir em plataformas digitais que agregassem diversos títulos e tornassem comum a prática de vender assinaturas não de periódicos isolados, mas de pacotes contendo um conjunto de títulos.

Já no século XXI, esse modelo passou a ser questionado e apontado como danoso para a livre disseminação do conhecimento, base da evolução da ciência. Pior: o modelo de negócio das editoras comerciais que publicam periódicos científicos passou a ser alvo de contestação por explorar a mão de obra acadêmica, cobrando preços exorbitantes daqueles (os pesquisadores) que lhes forneciam gratuitamente um caro produto, os artigos científicos, muitas vezes à custa de altos investimentos do setor público. O britânico The Guardian chegou a nominar as editoras científicas de "inimigas da Ciência" e de “capitalistas mais selvagens do planeta”, pela extorsiva política de preços praticada (Taylor, 2012).

Foi nesse contexto que o movimento conhecido como “acesso aberto" ganhou corpo, com a proposição de que os periódicos devem disponibilizar livremente seus conteúdos aos leitores. A partir dessa lógica, uma série de modelos de negócio suportando acesso aberto começou a aparecer, diversificando o cenário de disseminação da publicação científica (Costa \& Guimarães, 2010).

De fato, principalmente a partir do Budapest Open Access Initiative em 2001, os defensores do acesso aberto passaram a defender que os processos de comunicação científica deveriam privilegiar “a distribuição eletrônica de textos completos de revistas revisadas por pares pela Internet e sem restrições de acesso" (Costa \& Leite, 2016:37). Na América Latina, e no Brasil em particular, o acesso aberto passou a ser uma regra a partir de meados dos anos 2000, após a Comissão da Área de Administração, Ciências Contábeis e Turismo incluir nas diretrizes de avaliação dos periódicos a indicação de que passaria a ser valorizada "a disponibilidade online, sem custos (acesso livre ou aberto), do texto integral dos artigos publicados em periódicos, sejam estes impressos ou eletrônicos" (Capes, 2007:1).

Para complicar o cenário, o acesso aberto propiciou a emergência das chamadas "editoras predatórias", que exploram o mercado de publicações científicas promovendo um modelo em que os autores pagam para garantir acesso aberto aos leitores (Butler, 2013). Na prática, seriam “predatórias" porque dispensam qualquer critério científico na aprovação dos artigos e focam as tarifas cobradas dos autores. Ou seja, se as editoras científicas de modelo "fechado" exploram o trabalho dos autores, mas devolvem uma recompensa em reputação por terem publicado em um periódico reconhecidamente relevante para a comunidade científica, as predatórias, nem isso. É meramente "pagar para publicar”. 
Conectando essa discussão dos modelos de disseminação com o processo editorial apresentado anteriormente, percebe-se a relevância de entendermos melhor a questão dos custos de manter uma publicação científica. Se parece óbvio que manter um processo de publicação científica com qualidade implica custos relevantes, a discussão é sobre quem paga esses custos. Consolidou-se a lógica de que, enquanto as editoras tradicionais incentivam a ideia de o leitor pagar, o acesso aberto garante a gratuidade ao leitor, podendo caminhar para que o autor pague os custos de publicação. Mas esse não é certamente um jogo apenas de autores e leitores, e instituições de ensino e pesquisa e organismos de fomento, por exemplo, podem pagar para manter o acesso aberto a ambos os lados.

Independentemente de quem venha a pagar, o fato é que, para os periódicos brasileiros, que aderem compulsoriamente ao modelo de acesso aberto aos leitores, a discussão fica ainda mais complicada, principalmente em comunidades acadêmicas em que as alternativas para cobrar os autores não são bem-vistas. Assim, na maioria das vezes, quem paga acaba sendo uma instituição de ensino e pesquisa, pois sobram poucas alternativas para cobrir esses custos.

Some-se a isso o fato de a maioria esmagadora dos periódicos nacionais ser mantida por alguma instituição de ensino superior (IES), privada ou pública. Como não há retorno financeiro direto, o que essas instituições estão dispostas a investir nos periódicos em geral não cobre as necessidades para manter um padrão de qualidade exigido para colocá-los no patamar comparável ao dos periódicos internacionais vinculados a grandes editoras comerciais.

Isso favorece a criação de periódicos tocados de maneira “amadora", tanto no sentido positivo quanto no negativo, pois, embora sejam fruto de um trabalho dedicado, quase sempre voluntário, não conseguem atingir um padrão de qualidade à altura do que se encontra em mercados editoriais mais profissionalizados. $\mathrm{E}$, nos rankings de periódicos, observamos que os que estão mais próximos do topo são, via de regra, geridos por equipes profissionalizadas e com modelos desenhados com foco no "negócio" de publicação científica.

Quando nos colocamos diante da internacionalização, modelos de negócio devem começar a fazer parte das discussões sobre a sustentabilidade dos nossos periódicos. Ou seja, precisamos urgentemente colocar em pauta a discussão sobre fontes de receita consistentes para os nossos periódicos, indo além da busca de financiamento a fundo perdido, seja pelas IES ou por organismos de fomento, que gastam um valor nada desprezível comprando bases de periódicos. Já que a temática dos modelos de negócio tem lugar garantido no campo de administração, pesquisadores da área têm aqui um bom tema para explorar.

\section{ESTRATÉGIAS DE INTERNACIONALIZAÇÃO DE PERIÓDICOS BRASILEIROS}

$\mathrm{Na}$ era da globalização, internacionalizar está na pauta de todos. Os próprios periódicos brasileiros refletem esse movimento ao destacar a palavra-chave "internacionalização" entre as mais citadas nos artigos que publicam (Favaretto \& Francisco, 2017). Na mesma medida em que os programas de pós-graduação pressionam seus professores para publicarem “internacionalmente”, os periódicos nacionais também precisam se internacionalizar. Aqueles periódicos que não forem proativos no contexto da internacionalização não só continuarão invisíveis para autores estrangeiros, como também perderão importância para um grupo relevante de autores brasileiros. A questão é saber mais precisamente de qual internacionalização se está falando e como cada estratégia específica produz mais resultados com menos risco.

Diante desse cenário, os periódicos nacionais têm desenvolvido diversas iniciativas individuais de internacionalização. A seguir, vamos comentar três delas: publicação em inglês, adesão a editoras comerciais estrangeiras e investimento em chamadas de trabalho internacionais. Vale dizer que essas iniciativas não são autoexcludentes, ou seja, podem ser utilizadas de maneira combinada por quaisquer periódicos.

Há muito que diversos periódicos brasileiros em várias áreas adotam o inglês como única língua de publicação. 0 argumento é que o inglês é a única via para se alcançar visibilidade internacional, já que o português é uma língua muito pouco conhecida. Assim como no mundo dos negócios globalizados, a ciência globalizada só sabe falar em inglês.

Da mesma forma que o grego e o latim também já foram língua franca usada na transmissão de conhecimento em outras eras, seria difícil argumentar contra o uso do inglês como língua oficial dos periódicos brasileiros nos tempos atuais. Entretanto, além do impacto no custo do processo editorial com a adoção de uma língua que não é a nossa, deveríamos refletir melhor sobre algumas outras questões antes de adotar cegamente o inglês como língua oficial exclusiva.

Em primeiro lugar, não se pode confundir visibilidade com qualidade. Quem argumenta que os artigos mais citados estão em inglês, deveria considerar também que há muito artigo em inglês que não recebe citação alguma. Assim, para um artigo ser lido e, principalmente, citado por outros, é preciso bem mais do que traduzi-lo para o inglês. Colocar o foco exclusivo na publicação em inglês talvez nos desvie do principal objetivo a ser perseguido, 
ou seja, a qualidade científica e editorial do periódico. Se isso acontecer, corremos o risco de termos brasileiros publicando em inglês para outros brasileiros lerem, com a desvantagem de encarecer o processo editorial e reduzir a relevância local do que é publicado. A língua deve ser o meio, não o objetivo final, para se obter visibilidade com qualidade.

Um segundo ponto que não deveria ser desprezado na definição da "língua oficial” de um periódico é a notável evolução das ferramentas de tradução automáticas observada nos últimos anos. Se não estamos no ponto em que as traduções feitas por ferramentas automáticas possam ser consideradas confiáveis, não é difícil antecipar um tempo em que teremos acesso ao que pensam os que não falam a mesma língua que nós, sem necessariamente termos de usar o atalho comum do inglês. Isso significa que talvez não estejamos distantes de um futuro em que seria simplesmente irrelevante definir a língua de publicação de um artigo científico.

Mais complicado, porém, é o fato de a adoção do monolinguismo anglófono por parte dos periódicos brasileiros pode trazer riscos para a própria evolução do conhecimento científico, colocando barreiras para a disseminação de um saber mais diversificado. Como lembram Alves e Pozzebon (2013), a internacionalização do ensino superior tem levado ao enfraquecimento das tradições locais e nacionais, negligenciando outras línguas faladas em massa como mandarim, espanhol, árabe, hindi, russo, português e francês, o que compreende um universo de três bilhões de pessoas. No caso específico do ensino de administração, essa lógica coloca os pesquisadores não anglófonos numa “condição subalterna” ao optar por uma lógica externa à sua realidade e que define o que é conhecimento científico de qualidade (Rosa \& Alves, 2011:263). Paradoxalmente, mesmo aqueles que se pretendem opor à hegemonia anglosaxônica, para ter atenção na academia "internacional”, têm que publicar seus trabalhos em inglês para torná-los conhecidos por um público mais amplo (Gantman, Yousfi \& Alcadipani, 2015).

Se isso sugere que talvez o inglês venha mesmo a ser a língua universal da ciência na nossa era, não adianta lutar contra. Esse quadro faz emergir a segunda estratégia de internacionalização que gostaríamos de discutir, a de entregar os periódicos brasileiros às grandes editoras internacionais. É fato que essas grandes editoras conseguem garantir a qualidade necessária à disseminação internacional do conhecimento científico. E não é de se surpreender, por tudo o que foi dito anteriormente, que a maior qualidade de publicação dessas editoras só é possível por manterem uma estrutura compartilhada de publicação que atende a um grande número de periódicos ao mesmo tempo.
Larivière, Haustein e Mongeon (2015), em um amplo estudo sobre a indústria da publicação científica, cobrindo mais de 45 milhões de artigos entre 1973 e 2013, apontam uma crescente migração de periódicos para o controle das grandes editoras. 0 estudo identificou que, em 2013, metade dos artigos publicados em um dos repositórios mais seletivos era de apenas cinco grandes editoras.

Isso poderia sugerir que o caminho natural para nossos periódicos, que também querem ganhar um lugar de destaque junto aos principais periódicos internacionais, deveria ser mesmo o de migração para uma grande editora. Entretanto, outro achado da mesma pesquisa se mostra preocupante para quem aposta nessa estratégia para conseguir ampliar a sua visibilidade e, consequentemente, o seu impacto medido em volume de citações. Os autores ressaltam que, particularmente nas ciências sociais, o impacto médio dos artigos publicados nos periódicos que migraram para as grandes editoras permaneceu abaixo da média mundial. Ou seja, essa estratégia não produziu nenhuma melhoria no impacto dos periódicos, mesmo 10 anos após a migração.

A terceira estratégia de internacionalização a ser considerada são as chamadas de trabalho internacionais, os call for papers. Chamadas coordenadas por comitês que combinem brasileiros e convidados de outros países são um recurso o qual os periódicos nacionais deveriam considerar com mais frequência. Se é fato que alguns de nossos principais periódicos contam, em seu corpo editorial científico, com pesquisadores brasileiros bem articulados com parceiros internacionais, é o caso de criar condições para que essas parcerias sejam também trazidas para dentro dos nossos periódicos.

Os benefícios de consolidar essas parcerias internacionais em torno de uma chamada são por demais evidentes. Em primeiro lugar, o periódico passa a conhecer e trabalhar com editores internacionais convidados, alguns dos quais passariam a integrar o comitê científico permanente. Diferente do que alguns periódicos nacionais costumam fazer ao convidar pesquisadores estrangeiros para seu corpo editorial para atender à exigência de constituir uma lista "mais internacional”, a participação em uma chamada de trabalho ocorre com uma agenda bem-definida que inclui datas, responsabilidade de divulgação em redes de pesquisa, acompanhamento de pareceres etc. A partir do acompanhamento dessas chamadas, um trabalho de vários meses, e dos resultados obtidos ao seu final, o periódico pode avaliar o verdadeiro comprometimento dos parceiros internacionais. Com isso o periódico pode atrair parceiros internacionais que entendam o seu projeto editorial e ajudem a fortalecê-lo. Da mesma forma, os parceiros internacionais passam a conhecer melhor a condução do processo editorial e a qualidade do que 
se publica naquele periódico, aumentando as chances de citar seus artigos no futuro.

As dificuldades de fazer essa estratégia funcionar também são evidentes. Em primeiro lugar, é preciso convencer os brasileiros, atuais parceiros dos periódicos nacionais, a convidarem seus pares estrangeiros a participar de uma chamada de trabalho em um periódico "obscuro" e que não é considerado do primeiro time dos grandes periódicos estrangeiros. Periódicos que possuem bom desempenho em seus processos editoriais, com bons números (submissão, prazos etc.) para apresentar, costumam ser melhores candidatos a ter sucesso nessa empreitada. Além disso, boa representação regional (América Latina e ibéricos, para os brasileiros) também ajuda a atrair pesquisadores interessados em divulgar suas pesquisas nessas regiões.

Alguns aspectos do contexto do Brasil no mundo também ajudam na atração de pesquisadores internacionais. 0 primeiro deles é o evidente crescimento do interesse internacional pelo Brasil. Pesquisadores de alguns países desenvolvidos têm se dedicado cada vez mais a entender a nossa sinuosa lógica, algumas vezes com certa dificuldade para explicá-la com seus modelos. Pesquisadores de países em desenvolvimento têm interesse em conhecer alguns dos modelos que temos desenvolvido aqui e que podem ter impactos relevantes no caminho de desenvolvimento de seus países de origem.

O segundo aspecto é o aumento da responsabilidade internacional do Brasil. A identificação do nosso país num bloco diferenciado tanto dos que já são desenvolvidos quanto da maioria que ainda se denomina em desenvolvimento é um sinal importante. Obriga-nos a desenvolver uma pauta de pesquisa que permita abrir oportunidades de parcerias com instituições de países com os perfis mais variados. Podemos ajudar uns a nos entender melhor e também podemos conhecer mais sobre outros que querem adotar modelos desenvolvidos em nosso contexto.

Talvez a dificuldade maior seja mesmo convencer o pesquisador brasileiro a investir seu capital acadêmico - seus contatos internacionais - num periódico nacional. Considerando que todos os nossos mecanismos de incentivo premiam mais a participação num periódico internacional, ainda que este tenha desempenho, em seus processos editoriais, inferior aos de alguns dos nossos, o que ganharia o autor nacional em trazer seus contatos para um periódico brasileiro? No cenário atual, não muito. Ganharia certamente mais se investisse na sua parceria estrangeira para produzir um artigo com potencial de publicação em periódicos bem ranqueados internacionalmente.

Esse é um problema sobre o qual deveríamos todos, periódicos, pesquisadores, instituições de pesquisa e fomento, nos debruçar. Se já desenvolvemos um conjunto de mecanismos que premia a publicação internacional, por que não premiar também o trabalho de ajudar a internacionalizar nossos periódicos, ao trazer para os periódicos nacionais a participação de autores de instituições estrangeiras? Com esse tipo de incentivo concreto, certamente os periódicos brasileiros poderiam trilhar mais consistentemente o rumo à internacionalização.

Todas as três iniciativas de internacionalização mencionadas devem ser consideradas pelos periódicos nacionais, isoladamente ou combinadas. Todas têm seu valor e suas limitações, entretanto. Avaliar o potencial de cada uma em cada contexto específico é crucial para uma efetiva estratégia de internacionalização.

\section{CONSIDERAÇÕES FINAIS}

De tudo o que foi dito anteriormente, podemos extrair alguns pontos importantes. Em primeiro lugar, o fato de ser necessário investirmos na internacionalização de nossos periódicos sob pena de deixá-los perder até mesmo a sua relevância nacional. Ainda que isso possa ser colocado em perspectiva, pois temos uma enorme diversidade no nosso universo de publicação científica, pelo menos os principais periódicos da área de administração deveriam estar conscientes sobre a importância de um posicionamento internacional consistente.

Em segundo lugar, destacamos o foco no aperfeiçoamento dos processos editoriais como um caminho necessário rumo a qualquer iniciativa de internacionalização. Controle e ampla divulgação dos indicadores extraídos de todos os três grupos de atividades relacionados ao processo editorial são fundamentais.

Há que se considerar o amplo espaço de colaboração entre periódicos essencial para obter melhor sucesso na gestão dos processos editoriais. Como os custos de manter um processo editorial científico de qualidade são altos, devemos investir em plataformas comuns e profissionalizadas de gestão editorial que atendam vários periódicos simultaneamente, em vez de imaginar que cada periódico sozinho pode encontrar uma solução para melhorar seu status.

Uma alternativa para financiar esse tipo de plataforma comum seria uma mudança na política por parte de órgãos de fomento. Por exemplo, uma parte do recurso hoje gasto para financiar periódicos isoladamente ou comprando bases de periódicos internacionais poderia ser convertida para iniciativas que promovessem a agregação da gestão editorial de periódicos. Outra alternativa foi aventada em 2013 por um dos fundadores do SciELO, ao propor que este deixe de ser apenas um repositório e se transforme num verdadeiro publisher (SciELO, 2013). Nesse 
caso, talvez tivéssemos uma editora nacional com estrutura capaz de concorrer com as internacionais. Qualquer que seja a alternativa, não podemos depender apenas de grandes editoras internacionais como alternativa para definir o futuro de nossos periódicos, ainda que consideremos que elas também devem ter espaço para atuar em nosso país.

Outro aspecto da colaboração entre os periódicos fica explícito na participação nos repositórios internacionais mais relevantes. A RAE, o periódico nacional da área de administração com maior destaque internacional, fez uma simulação em 2015 e descobriu que dobraria o seu fator de impacto no JCR se outros periódicos nacionais do estrato $\mathrm{A}_{2} /$ Qualis estivessem na mesma base (Diniz, 2015). Isso acontece porque a $R A E$ é mais citada por RAC, RAP, RAUSP, Cadernos EBAPE.BR, O\&S etc. do que pelos periódicos estrangeiros. E esses periódicos também entrariam nessas mesmas bases em que a RAE já está com algum fator de impacto relevante. Com base nessa observação, fica claro que o processo de negociação para entrada nessas bases deve ser mais bem articulado entre os vários periódicos que já estão nesse caminho. A experiência de uns certamente pode contribuir para a entrada de outros. E todos ganham.

Por último, seria importante que nossos gestores acadêmicos, que tanto se esmeram para criar incentivos à internacionalização de nossa academia, considerassem que não basta premiar autores por publicarem internacionalmente, pois não construiremos uma academia forte sem periódicos também fortes. Precisamos entender que os mecanismos de incentivo também devem contemplar o pesquisador brasileiro que consegue atrair pares internacionais para publicar nos periódicos nacionais. Ao atrair autores internacionais relevantes para reforçar os nossos periódicos, seja como autores ou como membros de comitês científicos, esse pesquisador brasileiro está trabalhando para aumentar a relevância de toda a comunidade acadêmica brasileira ao dar maior visibilidade internacional aos periódicos nacionais.

\section{REFERÊNCIAS}

Alves, M. A., \& Pozzebon, M. (2013). How to resist linguistic domination and promote knowledge diversity? RAE-Revista de Administração de Empresas, 53(6), 629-633. doi:10.1590/So034-759020130610

Anderson, C. (2006). The long tail: Why the future of business is selling less of more. New York: USA. Hachette Books.

Associação Nacional de Pós-Graduação e Pesquisa em Administração. (2017). Boas práticas da publicação científica: Manual para autores, revisores, editores e integrantes de corpos editoriais. Recuperado de http://www.anpad.org.br/diversos/boas_praticas.pdf
Butler, D. (2013). The dark side of publishing. Nature, 495(7442), 433. doi:10.1038/495433a

Coordenação de Aperfeiçoamento de Pessoal de Nível Superior. (2007). Diretrizes de avaliação de periódicos 2007-2009. Comissão de Administração, Ciências Contábeis e Turismo. Coordenação de Aperfeiçoamento de Pessoal de Nível Superior (CAPES).

Costa, M. P. D., \& Leite, F. C. L. (2016). Open access in the world and Latin America: A review since the Budapest Open Access Initiative. Transinformação, 28(1), 33-46. doi:10.1590/2318 08892016002800003

Costa, S. M. D. S., \& Guimarães, L. V. D. S. (2010). Qualidade de periódicos científicos eletrônicos brasileiros que utilizam o sistema eletrônico de editoração de revistas (SEER). Informação \& Informação, 15, 75-92. doi:10.5433/1981-8920.2010v15n1espp75

Diniz, E. H. (2015). Internacionalização da RAE: O caminho trilhado entre 2009 e 2015. Editorial. RAE-Revista de Administração de Empresas, 55(6), 466-466. doi:10.159o/So034-759020150601

Dubini, P., Trani, F. di, \& Micheli, M. R. (2011). PEER Economics Report. Art, Science and Knowledge (ASK). Recuperado de http://www. peerproject.eu/fileadmin/media/reports/PEER_Economics_Report. pdf.

Favaretto, J. E., \& Francisco, E. R. (2017). Exploração do acervo da RAE-Revista de Administração de Empresas (1961 a 2016) à luz da bibliometria, text mining, rede social e geoanálise. RAE-Revista de Administração de Empresas, 57(4), 365-390. doi: 10.1590/So034759020170407

Gantman, E. R., Yousfi, H., \& Alcadipani, R. (2015). Challenging AngloSaxon dominance in management and organizational knowledge. RAE-Revista de Administração de Empresas, 55(2), 126-129. doi:10.1590/So034-759020150202

Larivière, V., Haustein, S., \& Mongeon, P. (2015). The oligopoly of academic publishers in the digital era. PloS one, 10(6), e0127502. doi:10.1371/journal.pone.0127502

Rosa, A. R., \& Alves, M. A. (2011). Pode o conhecimento em gestão e organização falar português? RAE-Revista de Administração de Empresas, 51(3), 255-264. doi:10.1590/So034-75902011000300006

Scientific Electronic Library Online. (2013). Entrevista Rogério Meneghini [on-line]. SciELO em Perspectiva. Scientific Electronic Library Online. Recuperado de http://blog.scielo.org/blog/2013/07/15/entrevistarogerio-meneghini/

Scientific Electronic Library Online. (2014). Critérios, política e procedimentos para a admissão e a permanência de periódicos científicos na Coleção SciELO Brasil. Scientific Electronic Library Online. Recuperado de http://www.scielo.br/ avaliacao/20141003NovosCriterios_SciELO_Brasil.pdf

Solomon, D. J. (2013). Digital distribution of academic journals and its impact on scholarly communication: Looking back after 20 years. The Journal of Academic Librarianship, 39(1), 23-28. doi:10.1016/j. acalib.2012.10.001

Taylor, M. (2012). Academic publishers have become the enemies of science. The Guardian. Recuperado de https://www.theguardian. com/science/2012/jan/16/academic-publishers-enemies-science 